\title{
The Association of Psychiatric Symptomatology With Patterns of Alcohol, Tobacco, and Marijuana Use Among Brazilian High School Students
}

\author{
Thiago M. Fidalgo, MD, PhD, ${ }^{1}$ Zila M. Sanchez, $\mathrm{PhD},{ }^{2}$ Sheila C. Caetano, MD, $\mathrm{PhD},{ }^{3}$ \\ Lucas O. Maia, MSc, ${ }^{2}$ Elisaldo A. Carlini, MD, ${ }^{2}$ Silvia S. Martins, MD, PhD ${ }^{4}$ \\ ${ }^{1}$ Department of Psychiatry, Universidade Federal de São Paulo, São Paulo, Brazil \\ ${ }^{2}$ Department of Preventive Medicine, Brazilian Center of Information on Psychotropic Drugs (CEBRID), Universidade Federal de São \\ Paulo, São Paulo, Brazil \\ ${ }^{3}$ Department of Psychiatry, Child and Adolescent Psychiatry Unit (UPIA), Universidade Federal de São Paulo, São Paulo, Brazil \\ ${ }^{4}$ Department of Epidemiology, Mailman School of Public Health, Columbia University, New York, New York
}

Background and Objectives: Studies have highlighted psychosocial factors associated with drug use among adolescents. Association of specific psychiatric comorbidity with substance use has not been properly established in Brazil. This study aimed to investigate alcohol, tobacco, and marijuana use by 15-18-year-old high school Brazilian students and to estimate associations with psychiatric symptoms.

Methods: A cross-sectional survey of 4,034 students from 128 public and private schools in São Paulo State was carried out using a twostep probability sample. Data were collected through self-report standardized questionnaires including questions on substance use patterns and the Strengths and Difficulties Questionnaire (SDQ). Key outcome variables were past-month use and past-month frequent use of alcohol, tobacco and marijuana. Questionnaires with missing information were excluded, resulting in a final sample of 2,532 adolescents. Weighted data was analyzed through logistic regressions, adjusted by gender and by socio-economic status (SES).

Results: Regarding SDQ total score, $43.6 \%$ of students had no psychiatric symptoms, $7.9 \%$ had subclinical symptoms and $48.5 \%$ presented clinically significant symptoms. Respondents with a clinically significant SDQ score were more likely to be past month alcohol $(\mathrm{aOR}=1.51 ; 95 \% \mathrm{CI} 1.22-1.88)$, tobacco $(\mathrm{aOR}=1.82 ; 95 \%$ CI 1.25-2.66), and marijuana ( $\mathrm{aOR}=1.79$; 95\% CI $1.21-2.64)$ users as compared to those with no symptomatology.

Discussion and Conclusions: Psychopathological symptoms were associated with alcohol, tobacco and marijuana use by 15-18-yearold adolescents. These associations should also be considered when planning public policies of mental health promotion.

Scientific Significance: This study discusses the importance of the association between psychopathological symptoms and substance use in a middle-income country, with high level of social inequalities, in a state representative sample. (Am J Addict 2016;25:416-425)

Received February 27, 2016; revised May 29, 2016; accepted July 6, 2016.

Address correspondence to Fidalgo, Departamento de Psiquiatria, Universidade Federal de São Paulo (UNIFESP), Ascendino Reis, 763, Vila Clementino, São Paulo (SP), Brazil. E-mail: marquesfidalgo@yahoo.com.br

\section{INTRODUCTION}

The prevalence of substance use tends to have a wide variation worldwide among high school students. ${ }^{1-7}$ Substance use among adolescents has been associated with mental health disorders or mental health symptoms. ${ }^{6,7}$ According to community studies of adolescent substance use and substance use disorders and psychiatric comorbidity, $60 \%$ of youths with substance use, abuse or dependence had a comorbid diagnosis. ${ }^{8}$ For example, conduct disorder (CD) and oppositional defiant disorder were most commonly associated with substance use, abuse or dependence, followed by depression. ${ }^{8}$ Other studies have corroborated the association between early onset of CD, and/or depressive symptoms with alcohol and illegal drug use during adolescence, ${ }^{9}$ especially among boys, who also seem to be more vulnerable to peer pressure and to be less able to self-monitor their emotions than girls. ${ }^{8,9}$

Studies to determine which specific mental health symptoms are associated with substance use among adolescents in different settings are crucial, so that proper public health policies can be enacted. This is particularly important in developing countries such as Brazil; where a wide gap of social inequalities is observed. Although it is the eighth wealthiest country in the world, it has important social discrepancies. São Paulo state accounts for $22 \%$ of Brazilian population (around 44 million inhabitants). Despite being the richest state in Brazil, social inequality is similar to that observed in a national level (with a Gini Index ${ }^{\mathrm{a}}$ of .474 in $2013^{10}$ ), the 14th most unequal state out of Brazilian 26 states and the Federal District. Our study focuses on high school students in São Paulo state, since previous studies have already established that socioeconomic status (SES) and neighborhood conditions have a major impact on mental health and substance use outcomes of adolescents. ${ }^{7}$ 
In Brazil, the prevalence of current alcohol use (pastmonth) ranges from $23.0 \%$ to $67.7 \%$, among adolescents of 10-19 years old. The prevalence of current tobacco use (past month) ranges from $2.4 \%$ to $22.0 \% .{ }^{11}$ Pinsky et al. found that frequent drinking (at least once a week) occurs in $9.1 \%$ of the Brazilian adolescent (14-17 years old) population. Binge drinking occurred in $52.9 \%$ of the boys and in $37.6 \%$ of the girls. ${ }^{12}$ Data from the I Brazilian National Alcohol Survey ${ }^{13}$ revealed a prevalence of cannabis use among Brazilian adolescents (12-17 years old) of 2.1\%. In a Brazilian national survey, Madruga et al. found that $2.8 \%$ of adolescents (14-19 years old) had used at least one illicit drug in the year before the survey. ${ }^{14}$ The most used illicit substances were marijuana $(1.6 \%)$, solvents $(1.1 \%)$, and crack/cocaine $(.5 \%)$. However, the association of psychiatric comorbidity among adolescents with past month and frequent alcohol, tobacco, and marijuana use has not been properly established in Brazil since most studies have only focused on examining prevalence estimates but not testing for associations.

\section{METHODS}

The main purpose of this study was to estimate associations of past-month frequent alcohol, tobacco, and marijuana use with concurrent mental health symptoms.

\section{Sample}

Data came from a representative sample of students at both public and private schools in São Paulo State, Brazil, with a classroom survey data collected from September 2013 to December 2013. The study's target population was designed as a representative sample of middle and high school students (from 6th to 12th grade). A two-step probability sample selection was used. In the first stage, schools were randomly drawn by strata in each one of the 15 administrative areas of the state. In the second stage, the sample was cluster randomized (classrooms). All students in sampled classrooms were invited to participate.

The sample size was set for a maximum $10 \%$ relative error and a 95\% confidence interval (CI). São Paulo State has 9,028 schools, 176 schools were contacted, 115 public schools, and 61 private schools. These numbers guaranteed that we kept the same ratio of public and private schools in the state in our study $(1.88: 1)$. Of this total, 128 agreed to participate in the survey (73\% school acceptance rate). Eleven public schools and 37 private schools refused to participate. This discrepancy was considered in the complex survey design.

Among the 9,411 students invited, $99.1 \%$ agreed to participate and the process generated a final sample of 9,326 students. In this paper, we focused on high-school

${ }^{a}$ Gini index measures the extent to which the distribution of income among individuals or households within an economy deviates from a perfectly equal distribution. A Gini index of 0 represents perfect equality, while an index of 100 implies perfect inequality. students (10th to 12 th grade) aged between 15 and 18 years old, comprising 4,034 students. Thirty-four subjects of the age range sample included in this study were excluded, as they positively answered the question about having ever used a fictitious drug. Sensitivity analyses were performed, investigating whether missing data on gender, SES and Strengths and Difficulties Questionnaire (SDQ) total and subscales scores would affect the final regression models. As there was no influence on results, we opted for excluding all questionnaires with missing values in any of these variables included in the model, resulting in a final sample of 2,532 adolescents.

\section{Data Collection and Instruments}

Anonymous standardized paper-and-pencil self-reported questionnaire data were gathered by a trained team of field researchers. They explained research objectives, anonymity, confidentiality and volunteering to the students and then distributed questionnaires. Data collection was conducted without a teacher or school member present in the classroom. In average, it took 45 minutes to complete the questionnaire. It was used a self-reported questionnaire with closed answers based on a World Health Organization instrument adapted to the Brazilian culture ${ }^{15,16}$ and the SDQ. ${ }^{17}$

\section{Measures}

The instruments included questions about alcohol, tobacco, and marijuana use, considering past month use (30 days prior to the research). Past month use was categorized in 1-5 days (low use), 6-19 days (frequent use), and 20 days or more (frequent use), as firstly defined by Smart et al. ${ }^{15}$ The instrument included questions about SES using a standardized survey assessment, known as the ABEP index. ${ }^{18}$ This index is based upon the possession of various types of household goods, the educational level of the head of the household, and number of housekeepers. Participants can be sorted to eight subgroups, according to their score, from A to E (where A1 is the highest economic strata).

In order to assess adolescent probable psychopathology in the past 6 months, the SDQ was used. ${ }^{17}$ This is a 25 -item screening measure of emotional and behavioral difficulties. It was designed for 3-17-year-old children/adolescents. The SDQ comprises five subscales: Emotional Symptoms, Conduct Problems, Inattention-Hyperactivity Symptoms, Peer Problems, and Prosocial Behavior. Its total score is achieved through the sum of all subscales scores, but Prosocial Behavior Subscale.

SDQ scores classify individuals as symptom-free (no psychopathology symptoms), subclinical (subclinical psychopathology symptoms) and clinical (clinically relevant psychopathology symptoms). The cut-off of each sub-scale used was: Emotional Symptoms (0-2, normal; 3, subclinical; 4-10, clinical), Conduct Problems ( $0-1$, normal; 2 , subclinical; 3-10, clinical); Inattention-Hyperactivity Symptoms ( $0-4$, normal; 5-6, subclinical, 7-10, clinical); Peer Problems (0-1, normal; 2-10, clinical) and Prosocial Behavior (8-10, normal; 5-7, subclinical; 0-4, clinical), according to Kovacs and Sharp ${ }^{19}$ 
recommendation. The Total Difficulties Score cut-off was as follows: 0-11, normal; 12, subclinical; and 13-40, clinical. Although the translated version of the SDQ has not yet been validated to the Brazilian context, it has been used in several studies with good results. ${ }^{20-23}$ A recent study ${ }^{24}$ has evaluated different cutoffs for the Brazilian version of the SDQ (different from the ones used in the analyses for this manuscript). The authors state that using higher cutoffs increases the specificity of the instrument, with little loss of its sensitivity. These higher cutoffs are better suitable for contexts of care that require more precise and faster procedures for diagnosis in which a clinician evaluation is not available. For screening purposes, as done in our study, the authors state that the usual cutoffs are reliable. ${ }^{24}$

\section{Key Outcome Variables}

The key response variables in this study were past-month use and past-month frequent use of alcohol, tobacco and marijuana.

\section{Covariates Under Study}

The predictors of central interest were the SDQ total score and the SDQ subscales score as described above. Two main logistic regression models were tested for each outcome variable: one model including the SDQ total score and a second model using SDQ subscales score separately. Gender and SES were included as control variables in all models.

Due to the inequality of distribution of Brazilian income, we defined four ranks of SES based upon the ABEP scale: A (A1 and A2), B (B1 and B2), C (C1 and C2), D/E (D and E). Due to small sample size, classes $\mathrm{D}$ and $\mathrm{E}$ were combined as a single category (see footnote ${ }^{b}$ ).

\section{Data Analysis}

First, we conducted exploratory analyses through basic contingency tables with Chi-square tests, followed by logistic regression for complex samples. We described the students' general sociodemographic variables, drug use and psychiatric symptomatology characteristics by weighted proportions. To estimate the association between the SDQ total and subscales scores and past-month use and frequent use of alcohol, tobacco and marijuana, we ran separate weighted logistic regression models in the overall sample for each substance use outcome of interest, adjusting for gender and SES.

Data were weighted to correct for unequal probabilities of selection into the sample. The complex survey design took into account the stratum (administrative region of the State in which schools were located), primary sampling unit (schools), clusters (classroom), the expansion weight, and the probability of drawing the student who answered the questionnaire.

${ }^{\mathrm{b}}$ ABEP provides eight different social economic strata (A1, A2, $\mathrm{B} 1, \mathrm{~B} 2, \mathrm{C}, \mathrm{D}$, and $\mathrm{E}$, where $\mathrm{A} 1$ is the highest). When data was collected annual family income ranges were as follows (average income): A1: U\$ 5875,00 or higher; A2: U\$ 3826,00; B1: U\$ 2008,00; B2: 1165,00; C1: U\$ 700,00; C2: U\$ 465,00; D: U\$ 324,00; E: U\$ 216,00 (quoting rate: U\$ $1,00=\mathrm{R} \$ 2,20$ ).
Analyses were performed using SPSS 20.0 and Stata 13.0, with the complex sample procedures to address variance estimation under the complex sample design in these regression models and in estimation of all 95\% CI. Results are presented via weighted proportions (wgt $\%$ ), adjusted Odds Ratios (aORs) and 95\% CI.

\section{Ethical Aspects}

The protocol was reviewed and approved by the Universidade Federal de São Paulo Research Ethics Committee (Protocol 192.052). The questionnaire did not include any information that could be used to identify the students. Participants could participate anonymously, decline to participate, leave questions unanswered, and interrupt their participation at any time.

\section{RESULTS}

\section{Descriptive}

Among the 2,532 students included in this study, most of them were girls; and from public schools. Past-month alcohol use rate was of $38.2 \%$. Frequent alcohol use rate was of $2.3 \%$. Tobacco use rates were of $8.8 \%$ and of $2.0 \%$ for past-month and frequent use, respectively. As for marijuana, use rates were of $7.2 \%$ and of $1.5 \%$. Regarding the SDQ total score, $43.6 \%$ of the students had no psychiatric symptoms; $7.9 \%$ had subclinical symptoms and $48.5 \%$ presented clinically significant symptoms. Detailed information is on Table 1.

Table 2 describes past month and frequent alcohol, tobacco, and marijuana use according to SDQ total and subscales scores in the study's sample. Positive SDQ Total Score and positive SDQ Conduct, Hyperactivity, Prosocial, and Peer subscales scores were statistically significantly associated with past month alcohol use. Positive SDQ Total Score and SDQ Conduct, Hyperactivity and Prosocial subscales scores were statistically significantly associated with past month tobacco use. Positive Conduct and Prosocial subscale score was statistically significantly associated with frequent tobacco use. Positive Conduct, Hyperactivity and Prosocial subscales scores were significantly associated with past month marijuana use. Positive Conduct, Hyperactivity, Prosocial and Peer subscales scores were significantly associated with frequent marijuana use.

\section{Total SDQ Score}

Respondents with a clinically significant SDQ score were more likely to be past month alcohol users, past month tobacco users and past month marijuana users as compared to those with no symptomatology. Detailed information is on Table 3.

\section{SDQ Subscores}

Reporting a clinical-level score in the SDQ Emotional subscale was significantly associated with infrequent tobacco use and with no past-month marijuana use. Having a subclinical score in the SDQ Conduct subscale was significantly associated 
TABLE 1. Sociodemographic, drug use and psychiatric symptomatology characteristics of 2,532 high-school students in Sao Paulo state, Brazil, 2013

\begin{tabular}{|c|c|c|c|}
\hline & \multicolumn{3}{|c|}{ Total $(n=2,532)$} \\
\hline & $n$ & wt $\%$ & $95 \% \mathrm{CI}$ \\
\hline \multicolumn{4}{|l|}{ School type } \\
\hline Private & 581 & 26.9 & $24.8-29.2$ \\
\hline Public & 1,951 & 73.1 & $70.8-75.2$ \\
\hline \multicolumn{4}{|l|}{ SES } \\
\hline A & 223 & 11.6 & $10.1-13.5$ \\
\hline $\mathrm{B}$ & 1,325 & 50.5 & $48.1-52.9$ \\
\hline $\mathrm{C}$ & 873 & 33.7 & $31.4-36.0$ \\
\hline $\mathrm{D} / \mathrm{E}$ & 111 & 4.2 & $3.3-5.2$ \\
\hline \multicolumn{4}{|l|}{ Alcohol } \\
\hline Past month use & 971 & 38.2 & $35.9-40.6$ \\
\hline Heavy use in the past month & 62 & 2.3 & $1.7-3.2$ \\
\hline \multicolumn{4}{|l|}{ Tobacco } \\
\hline Past month use & 211 & 8.8 & $7.5-10.3$ \\
\hline Heavy use in the past month & 48 & 2.0 & $1.4-2.8$ \\
\hline \multicolumn{4}{|l|}{ Marijuana } \\
\hline Past month use & 187 & 7.2 & $6.1-8.6$ \\
\hline Heavy use in the past month & 34 & 1.5 & $1.0-2.3$ \\
\hline \multicolumn{4}{|l|}{ SDQscores } \\
\hline \multicolumn{4}{|l|}{ Total } \\
\hline Non case & 1,121 & 43.6 & $41.2-46.0$ \\
\hline Borderline & 191 & 7.9 & $6.7-9.4$ \\
\hline Case & 1,220 & 48.5 & $46.0-50.9$ \\
\hline \multicolumn{4}{|l|}{ Emotional } \\
\hline Non case & 953 & 38.4 & $36.1-40.8$ \\
\hline Borderline & 398 & 15.4 & $13.8-17.3$ \\
\hline Case & 1,181 & 46.1 & $43.7-48.6$ \\
\hline \multicolumn{4}{|l|}{ Conduct } \\
\hline Non case & 722 & 29.0 & $26.8-31.3$ \\
\hline Borderline & 1,093 & 42.7 & $40.3-45.1$ \\
\hline Case & 717 & 28.3 & $26.2-30.6$ \\
\hline \multicolumn{4}{|l|}{ Hyperactivity } \\
\hline Non case & 1,624 & 63.6 & $61.2-65.9$ \\
\hline Borderline & 642 & 25.8 & $23.7-28.1$ \\
\hline Case & 266 & 10.6 & $9.2-12.2$ \\
\hline \multicolumn{4}{|l|}{ Prosocial } \\
\hline Non case & 730 & 27.7 & $25.6-29.9$ \\
\hline Borderline & 950 & 38.8 & $36.5-41.2$ \\
\hline Case & 852 & 33.5 & $31.2-35.8$ \\
\hline \multicolumn{4}{|l|}{ Peer } \\
\hline Non case & 685 & 27.0 & $24.9-29.2$ \\
\hline Case & 1,847 & 73.0 & $70.8-75.1$ \\
\hline
\end{tabular}

$\mathrm{wt} \%$, weighted proportions; CI, confidence interval; SES, sociodemographic status according to the ABEP scale (described in the Measures section); SDQ, strengths and difficulties questionnaire (subscales scores are described in the Measures section).

with past-month alcohol and past-month marijuana use. Having a clinical score in the SDQ Conduct subscale was significantly associated with past-month alcohol, tobacco, and marijuana use and with frequent tobacco use. Having a subclinical score in the
SDQ Hyperactivity subscale was associated with past-month marijuana use. Having a clinical score in the SDQ Hyperactivity subscale was associated with past-month alcohol, tobacco, and marijuana use and with heavy marijuana use. Having a clinical score in the SDQ Prosocial subscale were associated with pastmonth and frequent tobacco use. Lastly, having a clinical score in the SDQ Peer subscale were associated with frequent marijuana use. Detailed information is on Table 4.

\section{DISCUSSION}

Two substantive findings emerge from our analyses: 1) respondents with a clinically significant SDQ scores were more likely to be past month alcohol, tobacco, and marijuana users as compared to those without symptomatology; 2) different SDQ subscales scores were associated with different patterns of alcohol, tobacco, and marijuana use. These results emphasize the importance of psychopathological symptoms associated with substance use.

\section{Alcohol Use}

The relationship between alcohol use and psychopathology is widely known. In an Icelandic study with more than 10,000 adolescents aged $14-16$ years old, $5.4 \%$ of the sample met screening criteria for Attention Deficit Hyperactivity Disorder (ADHD). After controlling for gender and school grade, ADHD symptoms (but not ADHD diagnosis) were associated with alcohol use independent of other psychiatric symptoms. ${ }^{25}$ In an American cohort, 178 adolescents (113 with ADHD) were followed-up for 2 years, and the ones with ADHD, when compared with controls, were more likely to initiate alcohol use at early ages. ${ }^{26}$ This is a major concern, as the earlier the age of onset of alcohol use, the higher the risk of alcohol misuse in adolescence and adulthood, especially binge drinking patterns. In addition, it is already well established that the earlier the onset of alcohol use, the higher the risk of other drug use. ${ }^{16}$

The relationship between CD symptomatology and alcohol use has clinical significance as adolescent-onset alcohol abuse exacerbates the influence of childhood $\mathrm{CD}$ on late adolescent and early adult antisocial behavior. Those with co-occurring $\mathrm{CD}$ with early-onset alcohol abuse, compared with those showing only $\mathrm{CD}$, showed more violence in their criminal history and greater recreational drug use. ${ }^{27}$ The severity of lifetime alcohol-related and childhood-CD problems have also shown to be predictor variables of antisocial behavior. ${ }^{28}$ This association may also have impact on the formulation of preventive strategies, as treating $\mathrm{CD}$, especially in its early stages, might be effective for alcohol use prevention. ${ }^{29}$

Data from 2000 to 2004, of a US-national representative sample of 2,517 individuals aged 12-15 years old reported that individuals with $\mathrm{ADHD}$ and $\mathrm{CD}$, diagnosed based on caregiver responses to the Diagnostic Interview Schedule for Children, had an increased likelihood of alcohol use. ${ }^{30}$ In our sample, positive scores on the Conduct and Hyperactivity 


\begin{tabular}{|c|c|c|c|c|c|c|c|}
\hline & & \multicolumn{2}{|c|}{ Alcohol } & \multicolumn{2}{|c|}{ Tobacco } & \multicolumn{2}{|c|}{ Marijuana } \\
\hline & & $\begin{array}{l}\text { Past month use } \\
\qquad(n=971)\end{array}$ & $\begin{array}{l}\text { Heavy use } \\
\quad(n=62)\end{array}$ & $\begin{array}{l}\text { Past month use } \\
\qquad(n=211)\end{array}$ & $\begin{array}{l}\text { Heavy use } \\
\quad(n=48)\end{array}$ & $\begin{array}{l}\text { Past month use } \\
\quad(n=187)\end{array}$ & $\begin{array}{l}\text { Heavy use } \\
\quad(n=34)\end{array}$ \\
\hline \multirow{7}{*}{$\begin{array}{l}\text { SDQ total subscale } \\
\text { score }\end{array}$} & Non case & 34.1 & 2.4 & 6.6 & 1.9 & 5.6 & 1.2 \\
\hline & $(95 \% \mathrm{CI})$ & $30.6-37.7$ & $1.5-3.8$ & $5.0-8.6$ & $1.1-3.1$ & $4.2-7.5$ & $.7-2.3$ \\
\hline & Subclinical & 34.0 & 2.7 & 8.3 & 1.5 & 7.4 & 2.1 \\
\hline & $(95 \% \mathrm{CI})$ & $26.4-42.5$ & $1.0-7.2$ & $4.8-13.8$ & $.4-5.5$ & $4.0-13.1$ & $.6-6.4$ \\
\hline & Case & 42.7 & 2.2 & 10.8 & 2.2 & 8.7 & 1.7 \\
\hline & $(95 \% \mathrm{CI})$ & $39.3-46.2$ & $1.5-3.4$ & $8.8-13.3$ & $1.3-3.5$ & $6.9-10.8$ & $.9-3.0$ \\
\hline & $p$ value & 0.002 & 0.938 & 0.011 & 0.849 & 0.067 & 0.672 \\
\hline \multirow{7}{*}{$\begin{array}{l}\text { SDQ emotional } \\
\text { subscale score }\end{array}$} & Non case & 37.8 & 2.8 & 8.3 & 2.4 & 8.1 & 1.9 \\
\hline & $(95 \% \mathrm{CI})$ & $34.0-41.8$ & $1.8-4.4$ & $6.4-10.8$ & $1.5-4.0$ & $6.2-10.5$ & $1.1-3.3$ \\
\hline & Subclinical & 36.3 & 2.4 & 11.9 & 2.7 & 9.0 & 2.8 \\
\hline & $(95 \% \mathrm{CI})$ & $30.6-42.4$ & $1.2-4.9$ & $8.5-16.5$ & $1.3-5.8$ & $6.0-13.5$ & $1.3-5.7$ \\
\hline & Case & 39.2 & 1.9 & 8.1 & 1.4 & 5.9 & .8 \\
\hline & $(95 \% \mathrm{CI})$ & $35.8-42.8$ & $1.2-3.1$ & $6.3-10.3$ & $.8-2.4$ & $4.5-7.7$ & $.3-2.0$ \\
\hline & $p$ value & 0.683 & 0.533 & 0.153 & 0.224 & 0.149 & 0.072 \\
\hline \multirow{7}{*}{$\begin{array}{l}\text { SDQ conduct } \\
\text { subscale score }\end{array}$} & Non case & 26.1 & 1.8 & 5.0 & .7 & 3.0 & .7 \\
\hline & $(95 \% \mathrm{CI})$ & $22.2-30.4$ & $.9-3.4$ & $3.4-7.4$ & $.2-1.9$ & $1.8-5.0$ & $.2-2.4$ \\
\hline & Subclinical & 40.3 & 2.2 & 6.9 & 1.7 & 6.6 & .9 \\
\hline & $(95 \% \mathrm{CI})$ & $36.8-44.0$ & $1.3-3.6$ & $5.3-8.9$ & $1.0-2.9$ & $5.0-8.6$ & $.5-1.8$ \\
\hline & Case & 47.5 & 3.2 & 15.5 & 3.8 & 12.5 & 3.2 \\
\hline & $(95 \% \mathrm{CI})$ & $43.0-52.1$ & $2.0-5.0$ & $12.4-19.2$ & $2.4-6.0$ & $9.8-15.9$ & $1.9-5.5$ \\
\hline & $p$ value & $<\mathbf{0 . 0 0 1}$ & 0.310 & $<\mathbf{0 . 0 0 1}$ & 0.001 & $<\mathbf{0 . 0 0 1}$ & 0.003 \\
\hline \multirow{7}{*}{$\begin{array}{l}\text { SDQ hyperactivity } \\
\text { subscale score }\end{array}$} & Non case & 34.2 & 2.0 & 7.1 & 2.1 & 5.2 & 1.1 \\
\hline & $(95 \% \mathrm{CI})$ & $31.3-37.1$ & $1.3-3.0$ & $5.7-8.8$ & $1.4-3.1$ & $4.0-6.6$ & $.7-1.9$ \\
\hline & Subclinical & 43.3 & 3.3 & 9.4 & 1.8 & 8.7 & 1.4 \\
\hline & $(95 \% \mathrm{CI})$ & $38.5-48.1$ & $2.0-5.3$ & $6.9-12.7$ & $.8-3.6$ & $6.3-11.9$ & $.6-3.5$ \\
\hline & Case & 50.5 & 2.3 & 17.4 & 2.1 & 16.1 & 4.1 \\
\hline & $(95 \% \mathrm{CI})$ & $43.1-57.8$ & $.9-5.7$ & $12.5-23.6$ & $.8-5.5$ & $11.3-22.5$ & $1.9-8.8$ \\
\hline & $p$ value & $<\mathbf{0 . 0 0 1}$ & 0.285 & $<\mathbf{0 . 0 0 1}$ & 0.914 & $<\mathbf{0 . 0 0 1}$ & 0.021 \\
\hline \multirow{7}{*}{$\begin{array}{l}\text { SDQ prosocial } \\
\text { subscale score }\end{array}$} & Non case & 33.6 & 2.1 & 5.8 & .6 & 6.1 & .5 \\
\hline & $(95 \% \mathrm{CI})$ & $29.4-38.1$ & $1.2-3.9$ & $4.1-8.3$ & $.2-1.7$ & $4.2-8.7$ & $.2-1.3$ \\
\hline & Subclinical & 40.9 & 1.9 & 7.8 & 1.3 & 5.8 & 1.1 \\
\hline & $(95 \% \mathrm{CI})$ & $37.1-44.8$ & $1.1-3.1$ & $6.0-10.1$ & $.7-2.5$ & $4.3-7.9$ & $.5-2.5$ \\
\hline & Case & 39.0 & 3.1 & 12.3 & 3.9 & 9.8 & 2.9 \\
\hline & $(95 \% \mathrm{CI})$ & $35.0-43.1$ & $1.9-4.9$ & $9.8-15.5$ & $2.6-5.9$ & $7.6-12.6$ & $1.7-4.7$ \\
\hline & $p$ value & 0.048 & 0.327 & 0.001 & $<\mathbf{0 . 0 0 1}$ & 0.015 & 0.004 \\
\hline \multirow{5}{*}{$\begin{array}{l}\text { SDQ peer subscale } \\
\text { score }\end{array}$} & Non case & 42.3 & 2.0 & 10.1 & 1.2 & 8.0 & 2.6 \\
\hline & $(95 \% \mathrm{CI})$ & $37.8-47.1$ & $1.0-3.8$ & $7.6-13.3$ & $.5-2.9$ & $5.8-11.0$ & $1.4-4.9$ \\
\hline & Case & 36.7 & 2.5 & 8.3 & 2.3 & 7.0 & 1.1 \\
\hline & $(95 \% \mathrm{CI})$ & $34.0-39.5$ & $1.8-3.5$ & $6.8-10.0$ & $1.6-3.3$ & $5.7-8.5$ & $.7-1.9$ \\
\hline & $p$ value & 0.040 & 0.558 & 0.255 & 0.173 & 0.469 & 0.044 \\
\hline
\end{tabular}

SDQ, strengths and difficulties questionnaire (subscales scores were described in Section Measures); CI: confidence interval. Past-month use: use on the 30 days prior to the research; heavy use: use 20 days or more in the past month.

Bold values are the one with statistical significance, where $p<0.05$. 
SDQ subscales were also significantly associated with an increased likelihood of past-month alcohol use. Brinkman et al. reported that ADHD alone and $\mathrm{CD}$ alone did not increase the risk of alcohol or tobacco use. ${ }^{30}$ In our sample, however, these two clusters of symptoms were, by themselves, independently associated with alcohol and tobacco use. A mediating role of $\mathrm{CD}$ in the association between ADHD and alcohol use disorder has already been explored by others, thus, suggesting a developmental pathway from ADHD to CD and subsequent alcohol use disorders. ${ }^{31}$ In this line, early interventions in children with ADHD may prevent CD and subsequent onset of alcohol use. ${ }^{32}$

\section{Tobacco Use}

Concerning tobacco use and associated psychopathology, ADHD symptoms have been linked to greater rates of both lifetime and current smoking and early initiation of smoking. ${ }^{33-35}$ On the cohort of 178 individuals above mentioned, ${ }^{32}$ individuals with more ADHD symptoms were more likely to try cigarettes and 4-5 times more likely than controls to escalate to frequent cigarette use after trying tobacco. The Icelandic study ${ }^{25}$ also found an association between ADHD symptoms and tobacco use, independently of other psychiatric symptoms. Inattention and impulsivity seem to be the most important domains of ADHD on the establishment of this comorbid relationship. ${ }^{36} \mathrm{CD}$, once again, seems to be a mediate factor on the development of tobacco use during adolescence among those with ADHD symptoms. ${ }^{37}$ Data from a US-national representative sample of 2,517 individuals aged $12-15$ years old showed that individuals with ADHD and CD had an increased likelihood of tobacco use. ${ }^{30}$

Finally, a positive score on SDQ Emotional subscale was associated with infrequent tobacco use. The role of emotional symptoms on tobacco use has already been explored. Low emotional self-efficacy has already been associated to tobacco use, in a sample of more than two thousand high school students. ${ }^{38}$ The association between psychosocial problems and smoking is clearer for the onset of regularly smoking and less clear for the onset of tobacco use. ${ }^{39}$ Another study found that adolescents with lifetime alcohol/drug use with comorbid tobacco use had higher generalized anxiety symptoms and distress, and those with lifetime alcohol/drug use without comorbid tobacco use had higher panic disorder symptoms and anhedonia. Therefore, tobacco role on emotional symptoms remains a target for further investigation. ${ }^{40}$

\section{Marijuana Use}

The association between early marijuana use and subsequent problems, such as severe substance use disorders, cognitive impairment and poor social relationships has been widely studied. ${ }^{41-44}$ In a prospective, longitudinal study conducted with 1,088 adolescents, it was reported that conduct problems in childhood and early adolescence made a small but significant contribution to the risk for marijuana use 8 years later. ${ }^{45}$ In addition to that, in 2013, a study using a nationally representative sample of adolescent respondents to US-Monitoring the Future 


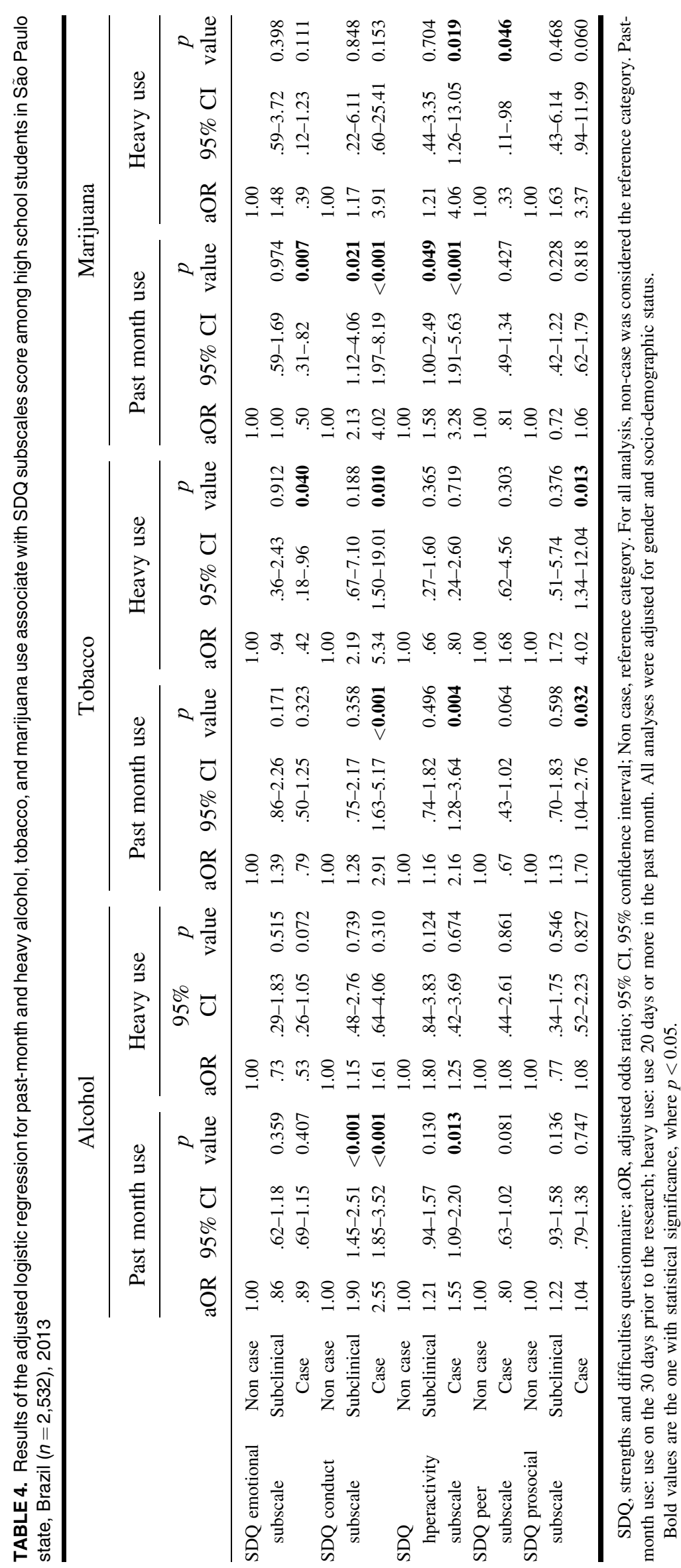


survey reported adolescents' depressive symptoms potentiate the relation of conduct problems to marijuana use. ${ }^{46}$ This is consistent with our finding that clinical and subclinical scores on SDQ Conduct subscale are associated to marijuana use. This has direct impact on policy formulations, as substance use prevention efforts should target both depressive symptoms and conduct problems. ${ }^{46}$ However, our findings concerning the SDQ Emotional subscale score is in the other direction, as we have found this to be a protective factor for past-month marijuana use. Previous study has found that marijuana use and temperament interact complexly in predicting risk for anxiety and depression. Authors discuss that this complex interaction may explain controversial findings concerning marijuana and emotional symptoms. ${ }^{47}$ As for the association of marijuana use and hyperactivity symptoms, it is known hyperactivityimpulsivity symptoms are associated with higher rates of early adult binge drinking and marijuana use. Therefore, this pattern may reflect a developmental course of vulnerability to elevated substance use in early adulthood. ${ }^{48}$ This also has impact on prevention policies, as among adolescents with ADHD, treatment with stimulant therapy has been shown to decrease risk for later marijuana abuse. ${ }^{4,50}$

\section{Subclinical Findings}

It is interesting that even subclinical positive scores on the SDQ were associated with some past-month and frequent substance use. This specific population of individuals with subclinical scores may be a potential target for clinical interventions, even though their clinical score is not positive yet. We speculate that their current substance use might be masking their actual mental health status. ${ }^{51}$ Moreover, both subclinical and clinical positive scores were associated to pastmonth use, but not to frequent use. This specific population may be a potential target for clinical interventions, even though their substance use is not frequent. In this case, we speculate that improving their mental health status can avoid them from frequent substance use. We conclude, then, that mental health policies should focus on these populations, as promoting mental health and providing early treatment for psychiatric symptoms may have a direct impact on mental health prevalence and its costs among adults.

\section{The Brazilian Context and International Implications}

These findings regarding the association of past-month and frequent alcohol, tobacco and marijuana use with psychopathological symptoms among adolescents gain more relevance when in perspective of the Brazilian health and social context. In a country with high levels of social inequalities, access to public health system may be limited. Mental health services, especially child and adolescence psychiatric facilities, are scarce and unequally distributed across the country. ${ }^{52}$ In addition to that, according to a recent survey, only a small proportion of children and adolescents with psychiatric disorders had been seen by a mental health specialist in the previous 12 months. ${ }^{52}$

A similar situation may be found in other low-middle-income countries. ${ }^{53,54}$ High levels of unplanned chaotic urbanization are a phenomena observed not only in São Paulo city and state, but also in other important cities and metropolitan regions in Latin America and in Asia. ${ }^{55}$ These regions usually concentrate high levels of social inequalities, which is a recognized risk factor for mental health symptoms. Better understanding the relationship between these inequalities and mental health and substance use rates of adolescents in low-middle-income countries is mandatory to better address mental needs of this population. Despite that, research focusing on these comorbidities are still scarce in these countries.

\section{Limitations}

Limitations are noted. Due to the fact that a self-report questionnaire was used, the questions were subject to interpretation by the participants and to a possible information bias. However, the anonymous nature of the survey and the absence of the teacher in the classroom could have helped to promote response validity. In addition, we included a question about a fictitious drug that allowed us to drop the questionnaires with proved bias information. Thirty-four subjects of the studied age range sample were excluded, as they positively answered the question about having ever used a fictitious drug. Some degree of nonparticipation (especially because of absence on the day of the survey) excluded some students from the analysis. However, the levels of participation were larger than those in the US Monitoring the Future study ${ }^{56}$ considering that almost all the students that were invited agreed to participated. Data missingness may also have influenced the results, although no difference was found in sensitive analysis. In addition, as this is a retrospective survey, we must consider the problems associated with recall bias. Nevertheless, the participants were still adolescents so the first use of alcohol was fairly recent. Lastly, it is important to note that as it is a cross sectional survey, as such, association does not imply causation. Especially concerning the SDQ Emotional subscale it is hard to understand why having a clinical score is negatively associated with heavy tobacco use and of marijuana use.

\section{CONCLUSION}

In summary, we set out to investigate whether there would be an association of specific psychopathological symptoms (evaluated by SDQ) and past-month and frequent alcohol, tobacco and marijuana use in a São Paulo state representative sample of 15-18-year-old adolescents. Positive scores on different SDQ subscales were associated with different use patterns of these substances. These associations should also be considered when planning public policies for mental health promotion, and prevention of mental health problems and of heavy substance use in adolescents.

State of São Paulo Research Foundation, Brazil (FAPESP Grant 12/04614-0, to Dr. E A Carlini). Dr. Martins is 
currently funded by the US National Institutes of Health (NIH), National Institute of Drug Abuse (NIDAR01DA037866 and R01DA039454), the Eunice Kennedy Shriver National Institute of Child and Human Development (NICHD-R01HD060072), and by a Columbia University President's Global Innovation Fund.

We would like to thank all the CEBRID staff, interviewers and study participants involved in this study.

\section{Declaration of Interest}

The authors report no conflicts of interest. The authors alone are responsible for the content and writing of this paper.

\section{REFERENCES}

1. Benjet C, Borges G, Medina-Mora ME, et al. Prevalence and sociodemographic correlates of drug use among adolescents: Results from the Mexican Adolescent Mental Health Survey. Addiction. 2007;102: 1261-1268.

2. Melchior M, Chastang JF, Goldberg P, et al. High prevalence rates of tobacco, alcohol and drug use in adolescents and young adults in France: Results from the GAZEL Youth study. Addict Behav. 2008;33: 122-133.

3. Organization of American States (OAS), Inter-American Drug Abuse Control Commission (CICAD). Comparative analysis of student drug use in Caribbean Countries: Antigua and Barbuda, Barbados, Dominica, Grenada, Guyana, Haiti, Jamaica, St. Kitts and Nevis, St. Lucia, St. Vincent and the Grenadines, Trinidad and Tobago, and Suriname: A Report on Student drug use in 12 Caribbean Countries. Washington, DC: OAS Publication; 2010.

4. Organization of American States (OAS), Inter-American Drug Abuse Control Commission (CICAD). Report on Drug Use in the Americas. Washington, DC: OAS Publication; 2011.

5. Atilola $\mathrm{O}$, Ayinde $\mathrm{O}$, Adeitan $\mathrm{O}$. Beyond prevalence and pattern: Problematic extent of alcohol and substance use among adolescents in Ibadan South-west Nigeria. Afr Health Sci. 2013;13:777-784.

6. Baheiraei A, Hamzehgardeshi Z, Mohammadi MR, et al. Alcohol and drug use prevalence and factors associated with the experience of alcohol use in Iranian adolescents. Iran Red Crescent Med J. 2013;15:212-217.

7. Manickam MA, Abdul Mutalip MH, Abdul Hamid HA, et al. Prevalence, comorbidities, and cofactors associated with alcohol consumption among school-going adolescentsin Malaysia. Asia Pac J Public Health. 2014;26: 91S-99S.

8. Armstrong TD, Costello EJ. Community studies on adolescent substance use, abuse, or dependence and psychiatric comorbidity. J Consult Clin Psychol. 2002;70:1224-1239.

9. McCarty CA, Wymbs BT, King KM, et al. Developmental consistency in associations between depressive symptoms and alcohol use in early adolescence. J Stud Alcohol Drugs. 2012;73:444-453.

10. Instituto Brasileiro de Geografia e Estatística (IBGE). Índice de Gini da distribuição do rendimento mensal de todos os trabalhos das pessoas de 10 anos ou mais de idade, ocupadas na semana de referência, com rendimento de trabalho, por sexo, segundo as Unidades da Federação. Síntese de Indicadores da Pesquisa Nacional por Amostra de Domicílios (PNAD). Rio de Janeiro: IBGE; 2013.

11. Barbosa Filho VC, Campos WD, Lopes AS. Prevalence of alcohol and tobacco use among Brazilian adolescents: A systematic review. Rev Saude Publica. 2012;46:901-917.

12. Pinsky I, Sanches M, Zaleski M, et al. Patterns of alcohol use among Brazilian adolescents. Rev Bras Psiquiatr. 2010;32:242-249.
13. Jungerman FS, Menezes PR, Pinsky I, et al. Prevalence of cannabis use in Brazil: Data from the I Brazilian National Alcohol Survey (BNAS). Addict Behav. 2010;35:190-193.

14. Madruga CS, Laranjeira R, Caetano R, et al. Use of licit and illicit substances among adolescents in Brazil-a national survey. Addict Behav. 2012;37:1171-1175.

15. Smart RG, Hughes DPH, Johnston LD. Methodology for Students Drug-Use Surveys. Geneva: World Health Organization; 1980.

16. Sanchez ZM, Locatelli DP, Noto AR, et al. Binge drinking among Brazilian students: A gradient of association with socioeconomic status in five geo-economic regions. Drug Alcohol Depend. 2013;127:87-93.

17. Goodman R. The strengths and difficulties questionnaire: A research note. J Child Psychol Psychiatry. 1997;38:581-586.

18. Associação Brasileira de Empresas de Pesquisa (ABEP). Critério de Classificação Econômica no Brasil [Criteria for Economic Classification in Brazil]. Rio de Janeiro: The Association; [cited 2016 Fev 26]. Available from: http://www.abep.org/criterioBrasil.aspx

19. Kovacs S, Sharp C. Criterion validity of the Strengths and Difficulties Questionnaire (SDQ) with inpatient adolescents. Psychiatry Res. 2014;219:651-657.

20. Curyand CR, Golfeto JH. Strengths and difficulties questionnaire (SDQ): A study of school children in Ribeirão Preto. Rev Bras Psiquiatr. 2003;25:139-145.

21. Woerner W, Fleitlich-Bilyk B, Martinussen R, et al. The Strengths and Difficulties Questionnaire overseas: Evaluations and applications of the SDQ beyond Europe. Eur Child Adolesc Psychiatry. 2004;13: II47-II54.

22. Fleitlich B, Cortázar PG, Goodman R. Questionário de capacidades e dificuldades (SDQ). Infanto Rev Neuropsiq Inf Adol. 2000;8:44-50.

23. Stivanin L, Scheuer CI. Assumpcao Jr FB. SDQ (Strengths and Difficulties Questionnaire): identificação de características comportamentais de crianças leitoras. Psic: Teor e Pesq. 2008;24:407-413.

24. Silva TB, Osório FL, Loureiro SR. SDQ: discrimative validity and diagnostic potential. Front Psychol. 2015;6:811.

25. Gudjonsson GH, Sigurdsson JF, Sigfusdottir ID, et al. An epidemiological study of ADHD symptoms among young persons and the relationship with cigarette smoking, alcohol consumption and illicit drug use. $J$ Child Psychol Psychiatry. 2012;53:304-312.

26. Sibley MH, Pelham WE, Molina BS, et al. The role of early childhood ADHD and subsequent $\mathrm{CD}$ in the initiation and escalation of adolescent cigarette, alcohol, and marijuana use. J Abnorm Psychol. 2014;123: 362-374.

27. Khalifa N, Duggan C, Howard R, et al. The relationship between childhood conduct disorder and adult antisocial behavior is partially mediated by early-onset alcohol abuse. Personal Disord. 2012;3: 423-432.

28. Howard R, Finn P, Jose P, et al. Adolescent-onset alcohol abuse exacerbates the influence of childhood conduct disorder on late adolescent and early adult antisocial behaviour. $J$ Forens Psychiatry Psychol. 2011;23:7-22.

29. Modesto-Lowe V. The conduct disorder-alcohol link: Implications for prevention strategies. Pediatrics. 2008;122:209.

30. Brinkman WB, Epstein JN, Auinger P, et al. Association of attentiondeficit/hyperactivity disorder and conduct disorder with early tobacco and alcohol use. Drug Alcohol Depend. 2015;147:183-189.

31. Lilienfeld SO, Waldman ID. The relationship between childhood Attention-Deficit Hyperactivity Disorder and adult antisocial behavior reexamined: The problem of heterogeneity. Clin Psychol Rev. 1990;10:699-725.

32. Tuithof M, ten Have M, van den Brink W, et al. The role of conduct disorder in the association between ADHD and alcohol use (disorder). Results from the Netherlands Mental Health Survey and Incidence Study2. Drug Alcohol Depend. 2012;123:115-121.

33. Riggs PD, Mikulich SK, Whitmore EA, et al. Relationship of ADHD, depression, and nontobacco substance use disorders to nicotine dependence in substance-dependent delinquents. Drug Alcohol Depend. 1999;54:195-205. 
34. Molina BS, Pelham WE. Substance use, substance abuse, and LD among adolescents with a childhood history of ADHD. J Learn Disabil. 2001;34:333-342.

35. Tercyak KP, Lerman C, Audrain J. Association of attention-deficit/ hyperactivity disorder symptoms with levels of cigarette smoking in a community sample of adolescents. J Am Acad Child Adolesc Psychiatry. 2002;41:799-805.

36. Burke JD, Loeber R, Lahey BB. Which aspects of ADHD are associated with tobacco use in early adolescence? J Child Psychol Psychiatry. 2001;42:493-502.

37. Upadhyaya HP, Carpenter MJ. Is attention deficit hyperactivity disorder (ADHD) symptom severity associated with tobacco use? Am J Addict. 2008;17:195-198.

38. Zullig KJ, Teoli DA, Valois RF. Emotional self-efficacy and alcohol and tobacco use in adolescents. J Drug Educ. 2014;44:51-66.

39. Crone MR, Reijneveld SA. The association of behavioural and emotional problems with tobacco use in adolescence. Addict Behav. 2007;32:1692-1698.

40. Chuang CW, Chan C, Leventhal AM. Adolescent emotional pathology and lifetime history of alcohol or drug use with and without comorbid tobacco use. J Dual Diagn. 2016;12:27-35.

41. Pope HG, Jr, Gruber AJ, Hudson JI, et al. Early-onset cannabis use and cognitive deficits: What is the nature of the association? Drug Alcohol Depend. 2003;69:303-310.

42. Agrawal A, Neale MC, Prescott CA, et al. A twin study of early cannabis use and subsequent use and abuse/dependence of other illicit drugs. Psychol Med. 2004;34:1227-1237.

43. Ellickson PL, Martino SC, Collins RL. Marijuana use from adolescence to young adulthood: Multiple developmental trajectories and their associated outcomes. Health Psychol. 2004;23:299-307.

44. Falls BJ, Wish ED, Garnier LM, et al. The association between early conduct problems and early marijuana use in college students. $J$ Child Adolesc Subst Abuse. 2011;20:221-236.

45. Shelton K, Lifford K, Fowler T, et al. The association between conduct problems and the initiation and progression of marijuana use during adolescence: A genetic analysis across time. Behav Genet. 2007;37:314-325.
46. Maslowsky J, Schulenberg JE. Interaction matters: Quantifying conduct problem $\times$ depressive symptoms interaction and its association with adolescent alcohol, cigarette, and marijuana use in a national sample. Dev Psychopathol. 2013;25:1029-1043.

47. Grunberg VA, Cordova KA, Bidwell LC, et al. Can marijuana make it better? Prospective effects of marijuana and temperament on risk for anxiety anddepression. Psychol Addict Behav. 2015;29:590-602.

48. Howard AL, Molina BS, Swanson JM, et al. Developmental progression to early adult binge drinking and marijuana use from worsening versus stable trajectories of adolescent attention deficit/hyperactivity disorder and delinquency. Addiction. 2015;110:784-795.

49. Biederman J. Pharmacotherapy for attention-deficit/hyperactivity disorder (ADHD) decreases the risk for substance abuse: Findings from a longitudinal follow-up of youths with and without ADHD. $J$ Clin Psychiatry. 2003;64:3-8.

50. Faraone SV, Wilens TE. Effect of stimulant medications for attentiondeficit/hyperactivity disorder on later substance use and potential for stimulant misuse, abuse, and diversion. J Clin Psychiatry. 2007;68:15-22.

51. McKernan LC, Nash MR, Gottdiener WH, et al. Further evidence of selfmedication: Personality factors influencing drug choice in substance use disorders. Psychodyn Psychiatry. 2015;43:243-275.

52. Paula CS, Bordin IA, Mari JJ, et al. The mental health care gap among children and adolescents: Data from an epidemiological survey from four Brazilian regions. PLOS ONE. 2014;9:e88241.

53. Alegría M, Canino G, Lai S, et al. Understanding caregivers' help-seeking for Latino children's mental health care use. Med Care. 2004;42:447-455.

54. Borges G, Benjet C, Medina-Mora M, et al. Treatment of mental disorders for adolescents in Mexico City. Bull World Health Organ. 2008;86:757-764.

55. The International Federation of Surveyors (FIG). Rapid Urbanization and Mega Cities: The Need for Spatial Information Management. Denmark, January, 2010.

56. Johnston LD, O'Malley PM, Bachman JG, et al. Monitoring the Future National Survey Results on Drug Use, 1975-2013: Volume I, Secondary School Students. Ann Arbor: Institute for Social Research, The University of Michigan; 2014. 